\title{
Gene Expression of Circulating Tumour Cells in Breast Cancer Patients
}

\author{
E. Bölke1*, K. Orth ${ }^{2 *}$, P. A. Gerber ${ }^{3}$, G. Lammering ${ }^{4}$, R. Mota $^{3}$, M. Peiper ${ }^{5}$, C. Matuschek ${ }^{1}$, W. Budach ${ }^{1}$, \\ E. Rusnak ${ }^{6}$, S. Shaikh 7 , B. Dogan ${ }^{8}$, H. B. Prisack ${ }^{8}$, H. Bojar ${ }^{8}$ \\ ${ }^{1}$ Department of Radiation Therapy and Radiation Oncology, University of Düsseldorf, Germany \\ ${ }^{2}$ Department of Surgery, KH Emden, Germany \\ ${ }^{3}$ Department of Dermatology, University of Düsseldorf, Germany \\ ${ }^{4}$ Maastro Clinic, Radiation Oncology, Maastricht, The Netherlands, \\ ${ }^{5}$ Department of Surgey, University of Düsseldorf, Germany \\ ${ }^{6}$ Department of Anesthesiology, State University of New York at Buffalo, USA, \\ ${ }^{7}$ Department of Anesthesiology UMass Memorial Medical Center Worcester, USA, \\ ${ }^{8}$ Department of Clinical Oncology, University of Düsseldorf, Germany
}

\begin{abstract}
Background: The diagnostic tools to predict the prognosis in patients suffering from breast cancer (BC) need further improvements. New technological achievements like the gene profiling of circulating tumour cells (CTC) could help identify new prognostic markers in the clinical setting. Furthermore, gene expression patterns of CTC might provide important informations on the mechanisms of tumour cell metastasation.

Materials and Methods: We performed realtime-PCR and multiplex-PCR analyses following immunomagnetic separation of CTC. Peripheral blood (PB) samples of 63 patients with breast cancer of various stages were analyzed and compared to a control group of 14 healthy individuals. After reverse-transcription, we performed multiplex PCR using primers for the genes ga733.3, muc-1 and c-erbB2. Mammaglobin1, spdef and $c$-erbB2 were analyzed applying realtime-PCR.

Results: ga733.2 overexpression was found in $12.7 \%$ of breast cancer cases, muc- 1 in $15.9 \%, m g b 1$ in $9.1 \%$ and spdef in $12.1 \%$. In this study, c-erbB2 did not show any significant correlation to BC, possibly due to a highly ambient expression. Besides single gene analyses, gene profiles were additionally evaluated. Highly significant correlations to $\mathrm{BC}$ were found in single gene analyses of ga733.2 and muc-1 and in gene profile analyses of ga733.3*muc-1 and GA7 ga733.3*muc- $1 * m g b 1 *$ spdef.

Conclusion: Our study reveals that the single genes ga733.3, muc-1 and the gene profiles ga733.3*muc-1 and ga733.3*3muc- $1 * m g b 1 * s p d e f$ can serve as markers for the detection of CTC in BC. The multigene analyses found highly positive levels in BC patients. Our study indicates that not single gene analyses but subtle patterns of multiple genes lead to rising accuracy and low loss of specificity in detection of breast cancer cases.
\end{abstract}

Key words: Mamma carcinoma, pcr, gene profile

Abbreviations: $\mathrm{BC}=$ breast cancer; $\mathrm{CTC}=$ circulating tumour cells; $\mathrm{PB}=$ peripheral blood; $c$-erbB2 = cellular avian erythroblastosis homologue B2; ga733.2 = major

\footnotetext{
* Equal contribution
}

gastrointestinal tumour-associated protein; muc-1 = mucin-1; mgb-1 = mammaglobin-typ $1 ;$ mRNA $=$ messenger RNA; PCR = polymerase chain reaction; RT$\mathrm{PCR}=$ reverse transcriptase polymerase chain reaction; $\mathrm{RT}=$ reverse transcriptase; $s p d e f=\mathrm{SAM}$ pointed domain-containing ETS transcription factor; FD = First Diagnosis; RD = Relapse Disease; $\mathrm{ABCD}=\mathrm{Ad}-$ nagen breast cancer detect kit; $\mathrm{ABCS}=$ Adnagen breast cancer select kit

\section{INTRODUCTION}

Circulating tumour cells (CTC) have been shown to play a major role in breast cancer (BC) tumour biology and may have a prognostic value in patients with metastatic disease [1] Primary tumour architectural characteristics may define its ability to metastize [2; 45-48]. Weak cell-cell connections lead to the dissemination of tumour cells via blood and lymph vessels [3]. Tumour cells entering the circulation depend on the organ microenvironment in order to be able to colonize tissues and to proliferate [4-7].

Altered gene expression is held responsible for a transformed behaviour of tumour tissue [8-11] and may distinguish CTC from healthy cells [12-13]. However, it remains unclear which genes allow a specific detection of CTC. Furthermore, inter- individual variations in gene expression levels due to certain genetic polymorphism additionally challenge these investigations.

The relatively small amount of CTC in PB of cancer patients led to the development of improved detection systems and cell enrichment $[1,14]$. Several approaches of immunomagnetic enrichment of CTC in samples of PB have been investigated [15-17]. Beads coated with monoclonal antibodies (mcAb) against epithelial surface proteins achieve a precise detection and extraction of epithelial and carcinoma cells from PB. Subsequently, enriched CTC can be detected by reverse transcriptase polymerase chain reaction (RTPCR) of altered marker genes putatively supposed to be tumour predictive. Several investigations have analysed various genetic markers to detect CTC. 
A French study showed an over expression of Mucin 1 (muc-1), a gene coding for a polymorphic epithelial surface phosphoprotein. This study included both patients with benign breast disease and advanced BC and indicated a significant correlation between the presence of muc1-positive cells and tumour staging. [18]. These findings were reproduced by Felton et al. showing similar results in patients with advanced disease [19].

ga733.3 (TACSTD1, Ep-CAM), a gene responsible for epithelial cell-cell adhesion by encoding a surface glycoprotein, is regarded as being present exclusively on epithelial cells [20]. Its use as a tumour marker has been controversially discussed [21]. Nevertheless Rao et al. [22] could demonstrate a decreased expression of ga733.2 in CTC as compared to primary tumour cells. This might indicate that decreased levels of this protein are crucial to the loss of cell adhesion which allows tumour cell to access the circulation. Notably Watson et al. documented an overexpression of SCGB2A2 (mammaglobin 1; $M G B-1$ ), a polypeptide member of the uteroglobin family, in BC [23-24]. Mammaglobin1-RT-PCR determination in PB was suggested as an adjunct to serum tumour markers by Lin et al. since the sensitivity sole $m g b 1$ in RT-PCR assays was considered as not convincing. Further studies compared the positivity of fresh $\mathrm{BC}$ tissue and $\mathrm{PB}$ [25]. Furthermore, a correlation between the frequency of $m g b 1$ overexpression in $\mathrm{PB}$ and the tumour stage of $\mathrm{BC}$ was described by Cerveira et al. [26].

Ghadersohi et al. described a strong expression of spdef in RT-PCR assays of BC tissues. Further investigations showed a superior tumour-association of this marker as compared to other cancer-associated molecules [27-30].

The purpose of the present study was to characterize CTC in PB of BC patients applying a commercially available system that targets the above mentioned genes.

\section{Material AND Methods}

This study was reviewed and approved by the institutional human subjects committee. BC patients and healthy individuals serving as controls provided informed-consent to all procedures.

\section{STUDY DESIGN}

Our study included 63 BC patients and 14 healthy controls. Patients ages ranged from 33 to 81 years with a median of 60 years. The age of controls varied be-

Table1. Clinical Staging. 63 breast cancer patients presenting with First Diagnosis (FD) or Relapse Disease (RD) were enrolled in this study. $\mathrm{G}$ represents disease staging according to the American Joint Committee on Cancer (AJCC).

\begin{tabular}{lccccc}
\hline G & 1 & 2 & 3 & $\mathrm{X}$ & $\Sigma$ \\
$\mathrm{FD}$ & 4 & 25 & 19 & 2 & 50 \\
$(\%)$ & $8 \%$ & $50 \%$ & $38 \%$ & $4 \%$ & $100 \%$ \\
$\mathrm{RD}$ & 0 & 8 & 4 & 1 & 13 \\
$(\%)$ & $0 \%$ & $61.5 \%$ & $30.8 \%$ & $7.7 \%$ & $100 \%$ \\
\hline
\end{tabular}

tween 24 and 61 with a median of 41.5 years. Fifty patients presented with first diagnosis (FD) of $\mathrm{BC}$ and 13 had relapse disease (RD) at the time of the PB collection. Disease staging according to the American Joint Committee on Cancer (AJCC) is summarized in Table 1. The median time interval between surgical treatment and study enrollment was 2.5 months for FD and 60 months for relapse disease (RD).

\section{Cell Separation}

Venous blood samples were collected in EDTA Vacutainer Tubes (Becton Dickinson, NJ USA) and processed within 2 hours using the immunomagnetic separation technique Adnagen Breast Cancer Select Kit (ABCS) (Adnagen, Langenhagen, Germany) following the manufacturer's instructions. This technique is based on an immunological selection of shedded non-haematological cells using antibodies, directed against epithelial and probably malignant surface antigens. Briefly, a combination of antibodies is loaded with magnetic particles and preserved in sodium-acid. Antibodies against ga733.3 and two different antibodies against epitopes of mucin-1 were used.

Before applying the blood samples, the immunomagnetic beads underwent three washing steps in a 1.5 $\mathrm{ml}$ tube using $1 \mathrm{ml}$ PBS (Gibco Invitrogen, Karlsrube Germany). Each step contained a bead separation in a magnetic bar system (MPC-S of Dynal). Subsequently 100 $\mu \mathrm{l}$ of immunomagnetic beads were added to $5 \mathrm{ml}$ of blood samples without any additions. Samples, including beads, were inserted in a tube rotator for 2 hours at 20 rounds per minute $(\mathrm{rpm})$ and room temperature (RT).

Using a larger magnetic bar system (MPC-L of Dynal Invitrogen, Karlsrube Germany), bead-loaded cells were accumulated on the MPC-L side. Subsequently, supernatants were removed cautiously and PBS $(5 \mathrm{ml})$ was added. PBS addition, MPC-L hold and removing of supernatants were repeated two times. At the end of this step, bead-cell-complexes were resuspended in $1 \mathrm{ml}$ of PBS and inserted in MPC-S. Supernatants were removed once more and complexes were resuspended in $200 \mu \mathrm{l}$ of $A B C S$ lysis/binding buffer. Finally, samples were inserted into MPC-S again. This time, supernatants, including cell lysates with native mRNA, were saved and stored at $-20^{\circ} \mathrm{C}$.

$A B C D$ was applied for RT and PCR steps of stored cell lysates. This kit contains lysis/binding buffer, oligo(dT)-25 beads, buffers $\mathrm{A}$ and $\mathrm{B}$, tris- $\mathrm{HCl}$ and Primermix. Additionally used kits included Sensiscript Reverse Transcription Kit and HotStarTaq Mastermix Kit (Qiagen) and Recombinant RNAsin (RNAse-Inhibitor Promega).

Briefly, oligo(dT)-coated beads (ABCD Dynabeads), targeting certain mRNA, were inserted in MPC-S and supernatants were removed. Beads were washed in lysis/binding buffer. This step was repeated once and 20 $\mu \mathrm{l}$ of dynabead was aliquoted subsequently to each sample of cell lysates. The mix of cell lysates and dynabeads was placed on a tube rotator for 10 minutes at $20 \mathrm{rpm}$ and RT. Samples were inserted in MPC-S and supernatants were removed. 
Next, samples were washed in series with buffer A, $\mathrm{B}$ and tris- $\mathrm{HCl}$ and inserted in MPC-S each time. Supernatants were removed. Washing steps with buffer A and $\mathrm{B}$ were processed twice, whereas tris- $\mathrm{HCl}$ was applied once.

After the final elimination of supernatants, we resuspended mRNA-bead-complexes in $29.5 \mu \mathrm{l}$ RNAsefree water and incubated them in a thermomixer for 5 minutes at $650 \mathrm{rpm}$ and $50{ }^{\circ} \mathrm{C}$.

\section{REVERSE Transcription (RT)}

Prepared RT-mix consisted of $4 \mu \mathrm{l} 10 \mathrm{x}$ buffer RT, $4 \mu \mathrm{l}$ dNTPs, $2 \mu \mathrm{l}$ RT (Qiagen, Hilden Germany) and $0.5 \mu \mathrm{l}$ RNAse inhibitor (Promega, Mannbeim Germany) for each sample of $29.5 \mu \mathrm{l} \mathrm{mRNA/bead-complexes.} \mathrm{RNAse-}$ free water was used as control. Transcription was performed in a thermocycler (Perkin Elmer 9600; $2^{\circ} \mathrm{C}$ / second) with following program:

$37^{\circ} \mathrm{C}$ for 60 minutes - reverse transcriptase step $93{ }^{\circ} \mathrm{C}$ for 5 minutes - inactivation step

cDNA suspension was stored on ice.

\section{Multiplex PCR}

Multiplex PCR (mPCR) was executed using $25 \mu \mathrm{l}$ of Hotstar Taq Mastermix (Qiagen, Hilden-Germany), $13 \mu \mathrm{l}$ distilled water, $4 \mu \mathrm{l}$ PrimerMix Breast Detect $(A B C D)$ and $8 \mu \mathrm{l}$ of cDNA suspension, RT-control, water as negative control or positive control $(A B C D)$ respectively. Primermix was a threefold combination of primers for ga733.2 (383 bp), muc-1 (293 bp), c-erbB2 (270 bp) and $\beta$-actin (114 bp) as control gene ${ }^{41}$. The total volume of $50 \mu \mathrm{l}$ was inserted in a thermocycler (Perkin Elmer 9600; $2{ }^{\circ} \mathrm{C} /$ second) and PCR was performed with 2 ${ }^{\circ} \mathrm{C} /$ second according to the following program:

\section{1. $95^{\circ} \mathrm{C}$ for 15 minutes - Taq activation}

2. $94^{\circ} \mathrm{C}$ for 1 minute

3. $60^{\circ} \mathrm{C}$ for 1 minute

4. $72^{\circ} \mathrm{C}$ for 1 minute

5. $72^{\circ} \mathrm{C}$ for 10 minutes - final elongation

6. $4{ }^{\circ} \mathrm{C}$

Steps 2 to 4 were repeated for 35 cycles. Finally, DNA suspensions were stored at $-20^{\circ} \mathrm{C}$. PCR products were analyzed in bioanalyzer (2100 - bioanalyzer Agilent, $C A, U S A)$ via DNA chips (version $25-1000 \mathrm{bp}$ ). Results were registered according to the fluorescence and via conversion in absolute cDNA concentration (ng/ $\mu \mathrm{l})$. As mentioned previously $\beta$-Actin was chosen as house keeping gene.

\section{REALTIME-PCR}

The expression of c-erbB2, mgb1 and spdef was determined quantitatively using high throughput real-time RT-PCR applying an ABI PRISM ${ }^{\circledR}$ 7900HT cycler (AME Bioscience, Toroed Norway). GUSBL1 (beta-like glucuronidase 1) was chosen as housekeeping gene. Probes were ordered as "ready to order" primer probe TaqMan gene expression assays, (Hs00170433_m1 for c-erbB2, HS00267190_m1 for mgb1, HS0017942_m1 for spdef,
Applied Biosystems, CA, USA). Each assay contained a pair of amplification primers and an additional TaqMan MGB oligonucleotide probes with a 6-FAM fluorescent dye linked to the $5^{\prime}$ end and one dark quencher on the $3^{\prime}$ end with a minor groove binder protein, increasing the probe melting temperature $(T m)$. Genes were selected according to frequently appearing gene expressions in our previous data (Affymetrix Chip HgU133A, 22283 genes in 83 breast cancer profiles vs 5 normal breast profiles) [31].

The PCR was run in a 96-well plates at a total volumes of $25 \mu$, containing the TaqMan Universal PCR Master Mix (dNTP, buffer, ROX and the AmpliTaqGold). The default thermal cycling protocol (as recommended by $\mathrm{ABI}$ ) was used for all target genes and the reference gene (initial step of $15 \mathrm{~min}$ at $95^{\circ} \mathrm{C}$ for the activation of the AmpliTaqGold and an amplification cycle of $15 \mathrm{sec}$ at $95^{\circ} \mathrm{C}$ and $1 \mathrm{~min}$ at $60^{\circ} \mathrm{C}$ for 40 cycles). Genes were quantified by determination of a threshold cycle numbers (ct). One common threshold was specified manually within the early exponential phase of fluorescence increase and it was used for all genes within one experiment. 'Transcriptase-minus' and 'water-only' controls were included.

The Her-2/neu status of $84.1 \%$ of our patients was determined routinely using immunhistochemistry (antibody against Her-2/neu: polyclonal DAKO 1:250). Staining results are classified into four levels according to the manufacturer's recommendation. Highly positive synthesis of Her-2/neu ( $\geq 2+$ ) was observed in 20 cases of BC $(20 / 53 ; 37.7 \%)$.

\section{Statistical Evaluation}

Statistical evaluation was performed using SPSS 11.5 for Windows (Microsoft Corp., SA, USA). Specific amplifications both in $\mathrm{MPCR}$ and realtime-PCR were registered in units specified for each gene and each group of patients separately. Results were recorded in dichotomized values. The threshold of dichotomized compilation was predetermined at $0.1 \mathrm{ng} / \mu \mathrm{l}$ for mPCR according to manufacturer's recommendation. Realtime-PCR results with (ct) values below 41 cycles were considered as positive. Afterwards, we searched for correlations between cases of FD, RD and healthy participants. Besides single gene evaluations, these searches also included multiple gene evaluations. Single-positive results were defined as samples that featured positive expressions for one gene, whereas twofold-positive results were defined as samples that featured positive expressions of at least two genes [32]. Correlations were checked either by Pearson's two-sided $\chi^{2}$-test for dichotomized values or by Pearson's bivariate correlation for values with two thresholds. The level of significance was determined as $\mathrm{p}$ $<0.05$.

\section{RESULTS}

EXPRESSION LEVELS OF ga733.2, muc-1 AND c-erbB2 IN PB THROUGH MPCR

Positive absolute PCR products of $\mathrm{BC}$ patients ranged from 0.1 to $8.4 \mathrm{ng} / \mathrm{ml}$ for ga733.3, from 0.12 to 6.3 $\mathrm{ng} / \mathrm{ml}$ for muc $^{-1}$ and from 0.13 to $1.1 \mathrm{ng} / \mathrm{ml}$ for c-erbB2. 
In the population of FD we observed specific amplifications for ga733.3 (5/50;10\%), muc-1 (6/50;12\%) and $c$-erbB2 $(7 / 50 ; 14 \%)$.

Cases of RD exposed overexpression rates for ga733.3 (3/13; 23.1\%), muc-1 (4/13; 30.8\%) and c-erbB2 $(1 / 13 ; 7.7 \%)$. Healthy controls showed positive expressions for ga733.3 (1/14; 7.1\%), muc-1 (1/14; 7.1\%) and $c$-erbB2 $(7 / 14 ; 50 \%)$ (Fig. 1).

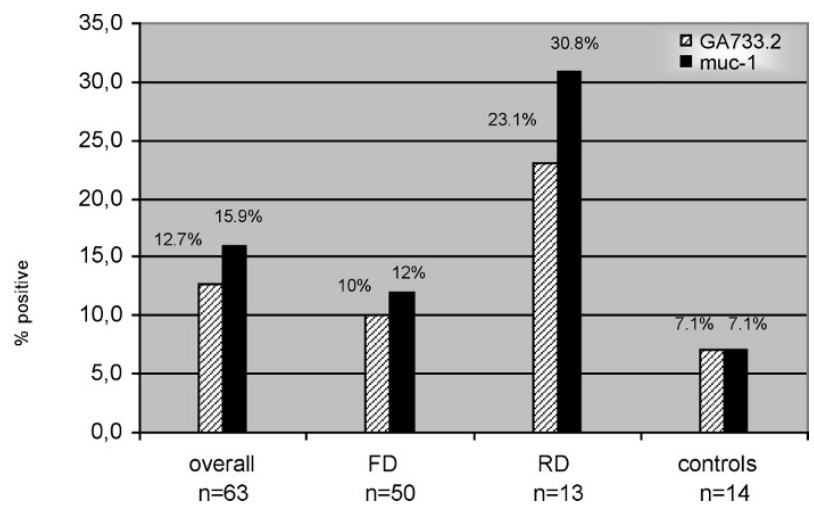

Fig. 1. ga733.3 and muc-1 expression. Multiplex pcr analyses of ga733.2 and muc-1 in peripheral blood. The "overall" panel refers to the patients with First Diagnosis (FD) and Relapse Disease (RD) excluding healthy controls.

\section{EXPRESSION LEVELS OF $m g b-1, s p d e f$ AND $c$-erbB2 IN PB} THROUGH RT-PCR

4 samples of FD and 2 cases of RD had neither $m g b 1$ specific nor non-specific transcription and were excluded from further examination. The same lack of transcription was found in 2 cases of FD and 1 case of RD concerning spdef. Hence we continued our investigation including 55 patients (44 FD and $11 \mathrm{RD}$ cases) concerning $m g b 1$ and 58 patients (46 FD and 12 RD cases) concerning spdef. Results of remaining products of patients ranged from 28 cycles to 39.5 cycles for $m g b 1$ and from 29.4 cycles to 40.9 cycles for spdef. Specific signals $(<41 \mathrm{ct}$ ) for $m g b 1$ were observed in $2 / 44$ $(4.5 \%)$ cases of FD and $3 / 11(27.3 \%)$ cases of RD, whereas this value was $0 / 14$ in healthy controls. spdef

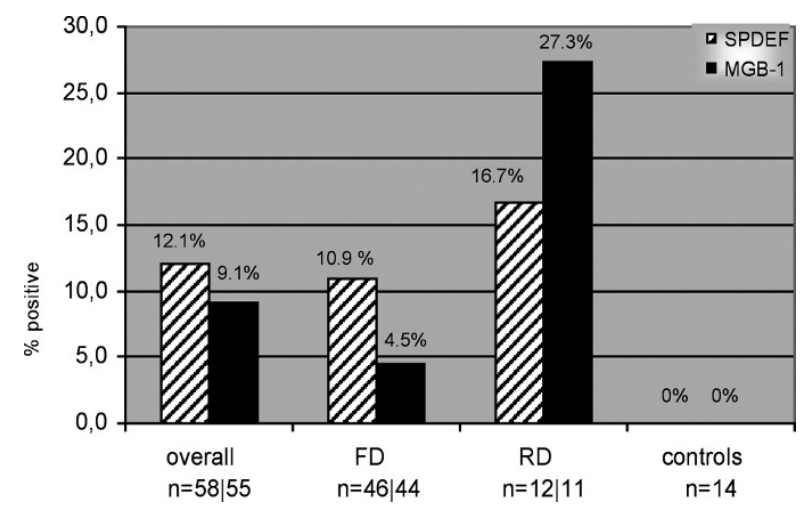

Fig. 2. spdef and $m g b 1$ expression. Positivity for spdef and mammaglobin1 in peripheral blood through RT-PCR. The "overall" panel refers to the patients with First Diagnosis (FD) and Relapse Disease (RD), excluding healthy controls. was detectable in 5/46 (10.9\%) cases of FD, in 2/12 $(16.7 \%)$ cases of RD and in $0 / 14$ healthy controls, respectively. C-erbB2 expression was found in 11/50 $(22 \%)$ cases of $\mathrm{FD}$, in $5 / 13(38.5 \%)$ cases of $\mathrm{RD}$ and in $10 / 14(71.4 \%)$ healthy controls. Results ranged from 39.9 cycles to 33.5 cycles (Fig. 2).

\section{View of Multiple-positive Cases}

The analyses of simultaneous gene expressions of ga733.3, muc-1, spdef and $m g b 1$ revealed 15 cases of BC with a positive expression of at least one of these genes. As results of $m g b 1$ were available in 55 cases, we limited this part of the investigation to this cohort of patients. Nine out of 44 positive cases were found in FD cases $(9 / 44 ; 20.5 \%)$ and 6 out of 11 in RD cases $(6 / 11 ; 54.5 \%)$.

\section{View of Simple-positive Expression of the Gene Profile ga733.2*muc- $1 * m g b 1 * s p d e f$}

The 15 participants of the BC group (15/55; 27.3\%) had at least one positive expression of the gene pattern GA7 ga733.3*muc-1*mgb1*spdef. Nine cases $(20.5 \%)$ belonged to the FD cohort and $6(54.5 \%)$ to RD cohort. Healthy controls also demonstrated positive results in 2 cases (14.3\%) (Fig. 3).

\section{VIEW OF TWOFOLD-POSITIVE EXPRESSION OF THE GENE PROFILE ga733.3*muc-1*mgb1*spdef}

Regarding at least two positive gene expressions in the pattern specified above, 10 cases $(18.2 \%)$ of BC patients and no healthy controls fulfilled this criterion. 6 positive cases were seen in the group of FD $(6 / 44 ; 13.6 \%)$ and 4 in the group of RD $(4 / 11 ; 36.4 \%)$ (Fig. 3$)$.

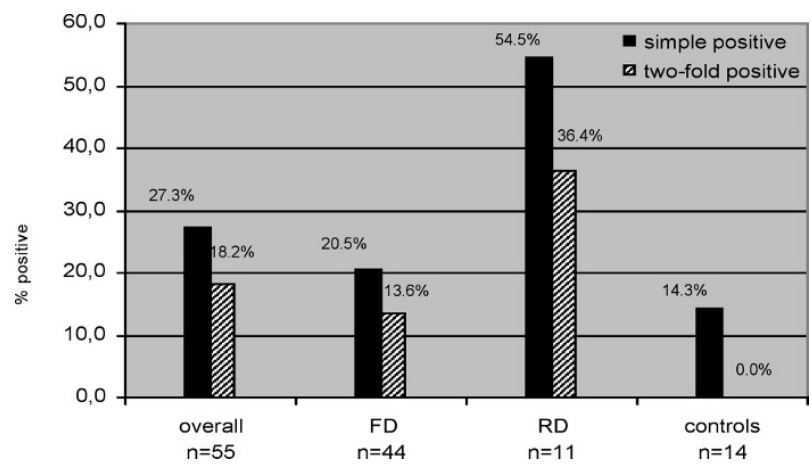

Fig. 3. ga733.2*muc $1 * m g b 1 * s p d e f$ expression. Simple positive or two-fold positivity for the gene pattern ga733.2*muc$1 * m g b 1 *^{*}$ spdef. The "overall" panel refers to the patients with First Diagnosis (FD) and Relapse Disease (RD), excluding healthy controls.

\section{Correlation of Expression Results to HER-2/NEU LEVEL VIA IHC}

Since we did not detect any significant correlation of Her-2/neu status and c-erbB2 mRNA in the results of our $\mathrm{MPCR}$ and realtime-PCR analyses, the investigation comparing Her-2/neu to other genes and respective gene profiles did not reach any significance. 


\section{DISCUSSION}

Today there is a growing interest in the gene characterization of CTC in BC, since it may provide important information on the mechanisms for tumour cell metastasation. We analyzed PB samples of BC patients presenting at our gynaecology department. The goal of our study was to determine marker genes with a high sensitivity for the detection of CTC. For this aim, we selected tools to detect CTC and to amplify DNA of predetermined genes, which are potentially overexpressed in tumour cells. Based on data provided by recent studies we used an immunomagnetic method to select circulating carcinoma cells [33-34]. An adverse effect on gene expression by application of direct immunomagnetic enrichment was excluded [35].

Several studies have described muc-1, c-erbB2 and $m g b 1$ as putative markers in BC. Yet, our not-preselected group of $\mathrm{BC}$ patients revealed a markedly lower overall expression of muc-1 as compared to other recent investigations [14-36]. Yet, tour results concerning mgb1 match those of Grunewald et al. [37]. Nevertheless higher expressions of $m g b 1 \quad(36.6 \%)$ in all stages of $\mathrm{BC}$ as compared to healthy controls were described by Lin et al. [38].

Additionally our study investigated ga733.3 and spdef, which have not been described commonly in BC cases, but which do possess putative marker characteristics [20, 28-30, 39]. Notably, ga733.3 and spdef showed nearly the same overall frequency of overexpression as the above mentioned cancer-associated marker genes. To the best of our knowledge, investigations of spdef in PB applying RT- and realtime PCR analyses have not been described in the literature, yet. Remarkably, the use of ga733.3 as marker was controversially discussed in recent studies due to its minimal basal expression in hematopoietic cells [21]. ga733.3 transcribes the surface molecule Ep-CAM in epithelial cells and serves as target molecule in immunomagnetic procedures of cell detection [41-42]. Thus, our study includes both Ep-CAM as immunomagnetic target transcript and ga733.3 as investigated gene using mPCR.

Comparisons of controls and BC patient groups revealed an increased frequency of ga733.3 (8/63 vs. $1 / 14)$, muc-1 (10/63 vs. $1 / 14)$, spdef (7/58 vs. 0/25) and $m g b 1$ (5/55 vs. $0 / 25)$. It is notable, that Zhong et al. (1999) demonstrated a high frequency of ga733.3 expression in healthy subjects $(40 \% ; 16 / 40)$ [20]. However, this study did not include any immunomagnetic processes to eliminate haematogenous cells. Another investigation of Rao et al. (2005) revealed a decrease of ga733.3 expression in CTC as compared to ga733.3 expression in tumour tissues, proposing a mechanism through which cells loose adhesion to enter circulation. Yet, this study did not include control subjects [22].

Muc-1 is described as a widely expressed gene in cells of epithelial origin. The literature shows controversial results regarding muc-1. On the one hand, Raynor et al. (2002) demonstrated that muc-1 transcribes a surface molecule, which was found in human non-malignant cells. Hence, a putative marker feature was denied in this investigation [43]. On the other hand, Felton et al. (2004) verified muc-1 expression in 8 of 9 advanced cases of BC, whereas only 1 of 11 healthy controls showed a positive expression. Moreover, they confirmed the expression of muc-1 in nonmalignant peripheral lymphocytes [44]. Our investigation revealed $15.9 \%$ positive expression in BC samples but only $7 \%$ in healthy controls. Notably, former approaches did not include any immunomagnetic separation method and were performed in restricted numbers of patients. Spdef ( $S A M$ pointed domain-containing ETS transcription factor, synonym PDEF) is a transcription factor involved in processes like cell proliferation, differentiation and invasion. It is mainly expressed in tissues with high fraction of epithelial cells. Recently, Ghadersohi et al. (2001) described higher expression of spdef in BC tissue as compared to healthy breast specimens [28]. In line with those results, we did not observe any positive results in the control group.

Most notably, in 2005, Van't Veer et al. emphasized the importance of gene expression profiling of multiple genes in BC, since single or double gene determination did not show satisfactory accuracy [45]. Here we demonstrate, that method-overlapping (mPCR and realtime-PCR) grouping of 4 genes, ga733.3, muc-1, spdef and $m g b 1$ exposes a positive result in $23.8 \%$ of our BC patient population. Fourfold profile (ga733.3* $m u c-1^{*}$ spdef* $\left.m g b 1\right)$ of controls levelled off at $14.3 \%$. To the best of our knowledge, our study represents the first investigation of fourfold gene profiles reported in the literature.

Taken together, our study shows that the single genes ga733.3, muc-1 and the gene profiles ga733.3* muc- 1 and ga733.3*2muc-1*mgb1*spdef can serve as markers for the detection of CTC in BC. Multigene analyses revealed highly positive levels in $\mathrm{BC}$ patients. Our study indicates that not single gene analyses but subtle patterns of multiple genes leads to rising accuracy and low loss of specificity in detection of BC cases

Yet, further studies are needed to better characterize CTC and to better understand metastatic processes in BC. Prospective studies with a larger patient populations and investigations of other target genes may identify aggressive profiles of BC and may influence therapeutic decisions.

Acknowledgement: This work is dedicated to Kim and Thomas Speer. Furthermore this work is a part of the thesis of Burak Dogan.

\section{REFERENCES}

1. Cristofanilli M, Hayes DF, Budd GT, et al. Circulating tumour cells: a novel prognostic factor for newly diagnosed metastatic breast cancer. J Clin Oncol 2005; 23: 1420-30.

2. Robinson BD, Sica GL, Liu YF, Rohan TE, Gertler FB, Condeelis JS, Jones JG. Tumour microenvironment of metastasis in human breast carcinoma: a potential prognostic marker linked to hematogenous dissemination. Clin Cancer Res. 2009; 15(7): 2433-41

3. Nicolson GL, Dulski KM, Trosko JE. Loss of intercellular junctional communication correlates with metastatic potential in mammary adenocarcinoma cells. Proc Natl Acad Sci U S A 1988;85:473-6. 
4. Welch DR, Steeg PS, Rinker-Schaeffer CW. Molecular biology of breast cancer metastasis. Genetic regulation of human breast carcinoma metastasis. Breast Cancer Res 2000; 2: 408-16.

5. Cho SY, Choi HY. Causes of death and metastatic patterns in patients with mammary cancer. Ten-year autopsy study. Am J Clin Pathol 1980;73:232-4.

6. Lee YT. Breast carcinoma: pattern of metastasis at autopsy. J Surg Oncol 1983;23:175-80.

7. Mochizuki S, Umemura S, Tokuda Y, Tajima T, Mitomi T, Osamura RY. A study of 46 cumulative breast cancer autopsy cases. Tokai J Exp Clin Med 1997; 22: 19-25.

8. Siegel PM, Dankort DL, Hardy WR, Muller WJ. Novel activating mutations in the neu proto-oncogene involved in induction of mammary tumours. Mol Cell Biol 1994; 14: 7068-77.

9. Oh JJ, Grosshans DR, Wong SG, Slamon DJ. Identification of differentially expressed genes associated with HER-2/neu overexpression in human breast cancer cells. Nucleic Acids Res 1999; 27: 4008-17.

10. Siegel PM, Ryan ED, Cardiff RD, Muller WJ. Elevated expression of activated forms of Neu/ErbB-2 and ErbB3 are involved in the induction of mammary tumours in transgenic mice: implications for human breast cancer. Embo J 1999;18:2149-64.

11. Gendler SJ, Lancaster CA, Taylor-Papadimitriou J, et al. Molecular cloning and expression of human tumour-associated polymorphic epithelial mucin. J Biol Chem 1990; 265: 15286-93.

12. Eltahir EM, Mallinson DS, Birnie GD, Hagan C, George WD, Purushotham AD. Putative markers for the detection of breast carcinoma cells in blood. Br J Cancer 1998; 77:1203-7.

13. Lambrechts AC, van 't Veer LJ, Rodenhuis S. The detection of minimal numbers of contaminating epithelial tumour cells in blood or bone marrow: use, limitations and future of RNA-based methods. Ann Oncol 1998;9:126976.

14. Ghossein RA, Bhattacharya S. Molecular detection and characterisation of circulating tumour cells and micrometastases in solid tumours. Eur J Cancer 2000;36: 1681-94.

15. Eaton MC, Hardingham JE, Kotasek D, Dobrovic A. Immunobead RT-PCR: a sensitive method for detection of circulating tumour cells. Biotechniques 1997;22:100-5.

16. Naume B, Borgen E, Beiske K, et al. Immunomagnetic techniques for the enrichment and detection of isolated breast carcinoma cells in bone marrow and peripheral blood. J Hematother 1997;6:103-14.

17. Hager G, Cacsire-Castillo Tong D, Schiebel I, et al. The use of a panel of monoclonal antibodies to enrich circulating breast cancer cells facilitates their detection. Gynecol Oncol 2005;98:211-6.

18. de Cremoux P, Extra JM, Denis MG, Pierga JY, Bourstyn E, Nos C, Clough KB, Boudou E, Martin EC, Müller A, Pouillart P, Magdelénat H. Detection of MUC1-expressing mammary carcinoma cells in the peripheral blood of breast cancer patients by real-time polymerase chain reaction. Clin Cancer Res. 2000;6(8):3117-22

19. Felton T, Harris GC, Pinder SE, Snead DR, Carter GI, Bell JA, Haines A, Kollias J, Robertson JF, Elston CW, Ellis IO. Identification of carcinoma cells in peripheral blood samples of patients with advanced breast carcinoma using RT-PCR amplification of CK7 and MUC1. Breast. 2004; 13(1): 35-41.

20. Zhong XY, Kaul S, Eichler A, Bastert G. Evaluating GA733-2 mRNA as a marker for the detection of micrometastatic breast cancer in peripheral blood and bone marrow. Arch Gynecol Obstet 1999; 263: 2-6.

21. Evaluating GA733-2 mRNA as a marker for the detection of micrometastatic breast cancer in peripheral blood and bone marrow. Zhong XY, Kaul S, Eichler A, Bastert G. Arch Gynecol Obstet. 1999; 263(1-2): 2-6.

22. Rao CG, Chianese D, Doyle GV, et al. Expression of epithelial cell adhesion molecule in carcinoma cells present in blood and primary and metastatic tumours. Int J Oncol 2005; 27: 49-57.

23. Watson MA, Darrow C, Zimonjic DB, Popescu NC, Fleming TP. Structure and transcriptional regulation of the human mammaglobin gene, a breast cancer associated member of the uteroglobin gene family localized to chromosome 11q13. Oncogene 1998; 16: 817-24.

24. Watson MA, Fleming TP. Mammaglobin, a mammaryspecific member of the uteroglobin gene family, is overexpressed in human breast cancer. Cancer Res 1996; 56: 860-5.

25. Roncella S, Ferro P, Bacigalupo B, et al. Human mammaglobin mRNA is a reliable molecular marker for detecting occult breast cancer cells in peripheral blood. J Exp Clin Cancer Res 2005; 24: 265-71.

26. Cerveira N, Torres L, Rocha P, et al. Highly sensitive detection of the MGB1 transcript (mammaglobin) in the peripheral blood of breast cancer patients. Int J Cancer 2004; 108: 592-5.

27. Ghadersohi A, Odunsi K, Lele S, et al. Prostate derived Ets transcription factor shows better tumour-association than other cancer-associated molecules. Oncol Rep 2004; 11: 453-8.

28. Ghadersohi A, Sood AK. Prostate epithelium-derived Ets transcription factor mRNA is overexpressed in human breast tumours and is a candidate breast tumour marker and a breast tumour antigen. Clin Cancer Res 2001; 7: 2731-8.

29. Feldman RJ, Sementchenko VI, Gayed M, Fraig MM, Watson DK. Pdef expression in human breast cancer is correlated with invasive potential and altered gene expression. Cancer Res 2003; 63: 4626-31.

30. Feldman RJ, Sementchenko VI, Watson DK. The epithelial-specific Ets factors occupy a unique position in defining epithelial proliferation, differentiation and carcinogenesis. Anticancer Res 2003; 23: 2125-31..

31. Modlich O, Prisack H-B, Munnes M, Audretsch W, Bojar $\mathrm{H}$. Predictors of primary breast cancers responsiveness to preoperative epirubicin/cyclophosphamide-based chemotherapy: translation of microarray data into clinically useful predictive signatures. J Transl Med 2005; 3: 32.

32. Greene FL PD, Fleming ID, et al. AJCC Cancer Staging Manual. 6th ed. New York: Springer; 2002.

33. Beitsch PD, Clifford E. Detection of carcinoma cells in the blood of breast cancer patients. Am J Surg 2000; 180: 446-8; discussion 8-9.

34. Hu XC, Wang Y, Shi DR, Loo TY, Chow LW. Immunomagnetic tumour cell enrichment is promising in detecting circulating breast cancer cells. Oncology 2003; 64: 160-5.

35. Woelfle U, Breit E, Zafrakas K, et al. Bi-specific immunomagnetic enrichment of micrometastatic tumour cell clusters from bone marrow of cancer patients. J Immunol Methods 2005; 300: 136-45.

36 Zippelius A, Pantel K. RT-PCR-based detection of occult disseminated tumour cells in peripheral blood and bone marrow of patients with solid tumours. An overview. Ann N Y Acad Sci 2000; 906: 110-23.

37. Grunewald K, Haun M, Urbanek M, et al. Mammaglobin gene expression: a superior marker of breast cancer cells in peripheral blood in comparison to epidermal-growthfactor receptor and cytokeratin-19. Lab Invest 2000; 80: 1071-7.

38. Lin YC, Chen SC, Hsueh S, et al. Lack of correlation between expression of human mammaglobin mRNA in peripheral blood and known prognostic factors for breast cancer patients. Cancer science 2003; 94: 99-102. 
39. Bostick PJ, Chatterjee S, Chi DD, et al. Limitations of specific reverse-transcriptase polymerase chain reaction markers in the detection of metastases in the lymph nodes and blood of breast cancer patients. J Clin Oncol 1998; 16: 2632-40.

40. Allard WJ, Matera J, Miller MC, et al. Tumour cells circulate in the peripheral blood of all major carcinomas but not in healthy subjects or patients with nonmalignant diseases. Clin Cancer Res 2004; 10: 6897-904.

41. Racila E, Euhus D, Weiss AJ, et al. Detection and characterization of carcinoma cells in the blood. Proceedings of the National Academy of Sciences of the United States of America 1998; 95: 4589-94.

42. Raynor M, Stephenson SA, Walsh DC, Pittman KB, Dobrovic A. Optimisation of the RT-PCR detection of immunomagnetically enriched carcinoma cells. BMC Cancer 2002; 2: 14.

43. Felton T, Harris GC, Pinder SE, et al. Identification of carcinoma cells in peripheral blood samples of patients with advanced breast carcinoma using RT-PCR amplification of CK7 and MUC1. Breast 2004; 13: 35-41.

44. van't Veer LJ, Paik S, Hayes DF. Gene expression profiling of breast cancer: a new tumour marker. J Clin Oncol 2005; 23: 1631-5.

45. Bölke E, Peiper M, Budach W, Matuschek C, Schwarz A, Orth K, Gripp S. (2007) Unilateral keloid formation after bilateral breast surgery and unilateral radiation Eur J Med Res. 12: 320-322
46. Matthaei H, Boelke E, Eisenberger CF, Alldinger I, Krieg A, Schmelzle M, Poremba C, Schellhammer F, Knoefel WT, Budach W, Peiper M (2008). Interdisciplinary treatment of primary hepatic angiosarcoma: emergency tumour embolization followed by elective surgery. Eur J Med Res. 4: 591-594

47 Matthaei H, Bölke E, Schmelzle M, Budach W, Orth K, Engers R, Cohnen M, Matuschek C, Gripp S, Knoefel WT, Peiper M (2008). Modern therapy of rectal carcinoma. Eur J Med Res. 13: 139-146

48. Peiper M, Bölke E, Orth K, Hosch SB, Rehders A, Matthaei A, Knoefel WT (2007) Current status of radical systematic lymphadenectomy in pancreatic cancer review of the literature Eur J Med Res 12: 47-53

Received: June 18, 2009 / Accepted: July 22, 2009

Address for correspondence:

Privatpraxis

Univ.-Prof. Dr. med. Hans Bojar

Hans-Günther-Sohl-Str. 12

40235 Düsseldorf

Germany

Tel.: $\quad+49(0) 211 / 91312220$

Fax: $\quad+49(0) 211 / 91312222$

Email: info@prof-bojar.de 